\title{
Visual management of performance with PROMETHEE productivity analysis
}

\author{
Alessio Ishizaka ${ }^{1}$ - Giuliano Resce ${ }^{2}$ - Bertrand Mareschal $^{3}$
}

Published online: 27 October 2017

(C) The Author(s) 2017. This article is an open access publication

\begin{abstract}
Multi-criteria decision analysis has been used to solve many problems. Here we describe an adaptation of PROMETHEE for measuring productivity. The results of PROMETHEE productivity analysis are displayed graphically, permitting the user to distinguish easily between four types of action: efficient, effective, frugal and inefficient actions. The productivity graph can be used for visual management and provides a simple, effective means of improving information communication within an organisation. It enhances transparency and promotes continuous improvement. Steps can be taken to improve ineffective actions using peer(s) on the frontier as example. To illustrate the use of the method we analysed the productivity of British universities. Only two old and two of the most recent universities were found to be on the frontier. Almost all of the most recent universities were classed as frugal and post-92 universities tended to be inefficient. Large old universities were generally classed as effective.
\end{abstract}

Communicated by A. Genovese, G. Bruno.

$\bowtie$ Alessio Ishizaka

Alessio.Ishizaka@port.ac.uk

Giuliano Resce

Giuliano.Resce@uniroma3.it

Bertrand Mareschal

bmaresc@ulb.ac.be

1 Portsmouth Business School, Centre for Operational Research and Logistics (CORL), University of Portsmouth, Richmond Building, Portland Street, Portsmouth PO1 3DE, UK

2 Dipartimento di Economia, Università degli Studi di Roma Tre, Via S. D’Amico, No. 77, 00145 Rome, Italy

3 Solvay Brussels School of Economics and Management, Université Libre de Bruxelles, Brussels, Belgium
Keywords PROMETHEE - MCDA - Visual management . Efficiency $\cdot$ Effectiveness $\cdot$ Frugality

\section{Introduction}

In today's increasingly globalised, complex economy that is flooded with data, decision-makers have more need than ever to manage their business efficiently. To help them achieve this, we have developed a new multi-criteria performance management method that provides input for visual management and continuous improvement initiatives.

The most commonly used method of performance estimation is Data Envelopment Analysis (DEA; Charnes et al. 1978; Banker et al. 1984). The basic idea behind DEA is that global performance is given by the ratio of the sum of weighted output levels to the sum of weighted input levels (Chen and Iqbal Ali 2002). Although this useful method allows one to estimate performance without any ex ante assumptions about the form of the production function it has two main drawbacks. The first is that in a multi-input/multioutput context the evaluation is made in a 'black box' that does not give the decision-maker a clear visual representation of the frontier. This feature of DEA makes it more difficult to disseminate the information it provides within an organisation. The second drawback of DEA is that evaluation becomes problematic when the output-input ratios do not make much sense, as is the case when scale-independent data (ratios or indices) are mixed with scale-dependent data (Dyson et al. 2001; Cooper et al. 2007; Cook et al. 2014). Consider, for example, evaluation of universities' performance; if an output such as research quality-evaluated on a 1-10 index and therefore not linked to the size of the university-is compared with an input such as expenditure, which is scale-dependent, then a small university will 
inevitably be rated efficient and the efficiency index is meaningless. Various artifices have been proposed to circumvent this problem; one of the most frequent is multiplying the scale-independent variable by the level of one of the scaledependent variables. Obviously, the results are dependent on the variable chosen for the transformation, and this choice is problematic in the multi-input/multi-output case (Dyson et al. 2001; Cooper et al. 2007; Cook et al. 2014).

Another stream are the multi-criteria decision analysis (MCDA) methods. The analogy with DEA is striking if we replace the name "DMU" with "actions", "outputs" with "criteria to be maximised" and "inputs" with "criteria to be minimised". They have been developed to help decisionmakers when they are faced with ambiguous and conflicting data (Ishizaka and Nemery 2013). Moreover, MCDM can also help to analyse the performance of actions (also called alternatives). For example, da Rocha et al. (2016) evaluated the operational performance of Brazilian airport terminals using Borda-AHP, Longaray et al. (2015) used MACBETH to evaluate Brazilian university hospitals, Nemery et al. (2012) evaluated the innovation capacity of small and medium enterprises (SMEs), Ishizaka and Pereira (2016) developed a hybrid ANP-PROMETHEE method for evaluating employee performance and Galariotis et al. (2016) used MAUT to evaluate French local governments.

Performance evaluations are often given in the form of a ranking, which represents a synthesis of the data and hides important information. In this paper we report the development of a new MCDA method, PROMETHEE Productivity analysis (PPA), which coupled with a productivity graph, permits one to distinguish between four categories: efficient, effective, frugal and ineffective actions.

Performance analysis generally serves as a basis for developing corrective actions as part of a continuous improvement framework. It is important to have an understanding of the current situation, but the required analytical process can be complicated. Possible corrective strategies also need to be identified and discussed and it has been proposed that visual analytical tools offer a way of presenting, justifying and explaining them effectively and transparently (Nemery et al. 2012; Ishizaka and Pereira 2016). Visual representation permits users to take in a large amount of information simultaneously as it maximises human capacity to perceive, understand and reason about complex data and situations. Visual representations promote high-quality human judgement with limited investment of the analysts' time (Thomas and Cook 2006). Visual management has largely been used in production management in the forms of visual stream mapping, flow charts and area name boards (Tezel et al. 2016). It has also been coupled with MCDA outputs. Two popular graphical methods are the GAIA plane, which represents multi-dimensional information in a two-dimensional space whilst preserving as much of it as possible (Ishizaka et al.
2016) and stacked bar charts, which allow the user to see the pros and cons of each action (Ishizaka and Pereira 2016).

Here we developed a productivity graph that allows actions to be compared against each other. It can be used to identify more efficient peers in order subsequently to follow their example. The new multi-criteria performance management method (Sect. 2) coupled with its visual management tool is illustrated by an evaluation of the performance of British universities (Sect. 3).

\section{PROMETHEE productivity analysis}

\subsection{Problem formulation}

A large number of methods of solving multi-criteria problems have been developed, and this trend seems set to continue. Wallenius et al. (2008) showed that the number of academic publications related to MCDA is steadily increasing. This proliferation is not only due to researchers' impressive productivity but also to the development of MCDA methods specific to certain types of problems. Roy (1981) has described four types of problem:

1. Choice problem $(P \cdot \alpha)$ : the goal is to select the single best action or to reduce the group of actions to a subset of equivalent or similar actions.

2. Sorting problem $(P \cdot \beta)$ : actions are sorted into predefined, ordered categories. This method is useful for repetitive and/or automatic use. It can also be used for screening in order to reduce the number of actions subjected to more detailed consideration.

3. Ranking problem $(P \cdot \gamma)$ : actions are placed in decreasing order of preference. The order can be partial, if we consider incomparable actions, or complete.

4. Description problem $(P \cdot \delta)$ : the goal is to help to describe actions and their consequences.

Additional problem formulations have also been proposed:

5. Elimination problem (Bana e Costa 1996): a particular case of the sorting problem.

6. Design problem: the goal is to identify or create a new action that will meet the goals and aspirations of the decision-maker (Keeney 1992).

PROMETHEE (Brans and Mareschal 1994, 2005) is a multi-criteria method that belongs to the family of the outranking methods. It has been easily adapted to solve all the problems formulations (Mareschal et al. 2010). The aim of this paper is to present a MCDA-based solution to a new type of problem, namely the productivity problem. The 
majority of MCDA tools allow to assess the effectiveness: namely an alternative is said to be effective when it meets the output target. The MCDA methods allow to collapse multidimensional outputs into a single index that can be used as measure of effectiveness. The major shortcoming of effectiveness is that it is based just on the levels of output, and it does not deal with resource used to produce the output. For instance, an alternative could be ineffective because it has got a very limited resource. This is the reason why the most commonly used measure of performance is productivity (Ray and Chen 2015).

7. Productivity problem: the goal is to assess the efficient utilisation of resources in the production.

The usual measure of productivity is a single indicator like output per worker. However, when there is more than one input (like labour and capital) and more than one output, the ratio Output/Workers fails to account for the use of all the inputs used and all the output produced. In order to overcome this shortcoming, we propose a MCDA method to build an aggregate measure of the inputs, and an aggregate measure of the outputs, and we assess productivity by means of relation between these two indices.

In the next subsections, we explain how we adapted PROMETHEE to solve this problem.

\subsection{Method description}

As with any other multi-criteria method, we consider a set of $n$ possible actions $A=\left\{a_{1}, a_{2}, \ldots, a_{n}\right\}$ which are evaluated according to a set of $k$ criteria $C=\left\{c_{1}, c_{2}, \ldots, c_{k}\right\}$. The main difference between PPA and the other methods in the PROMETHEE family is that the criteria are split into two groups: input and output criteria. The processing of the data is kept separate. For each criterion $c_{i}$, and for each pair of actions $(a, b)$, the decision-maker expresses his/her preference by means of a preference function $P_{i}$ : the preference degree $P_{i}(a, b)$ is a number between 0 and 1 that indicates the extent to which action $a$ is preferred to action $b$ based on criterion $c_{i}$. Six typical preference function shapes are proposed (Brans and Vincke 1985): usual function, U-shape, Level (Fig. 2), V-shape, V-shape with indifference (Fig. 1) and Gaussian (Fig. 3). The usual ( $p=q=0)$, V-shape $(p=0)$ and $\mathrm{U}$-shape $(p=q)$ are particular cases of the Vshape with indifference (Fig. 1), where $p$ is the indifference and $q$ the preference threshold on the axis $d$, which represents the score of an action on the given criterion.

A multi-criteria preference index is then calculated as a weighted sum of the single-criterion preference degrees:

$$
\pi(a, b)=\sum_{i=1}^{k} P_{i}(a, b) \cdot w_{i} .
$$

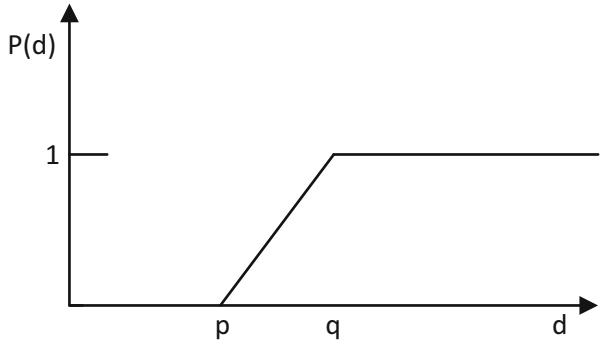

Fig. 1 V-shape with indifference preference function

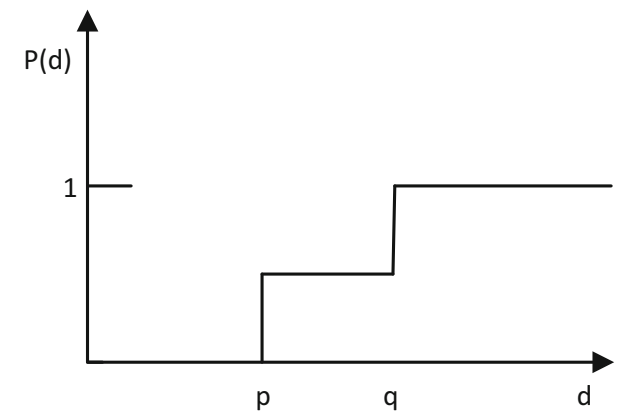

Fig. 2 Level preference function

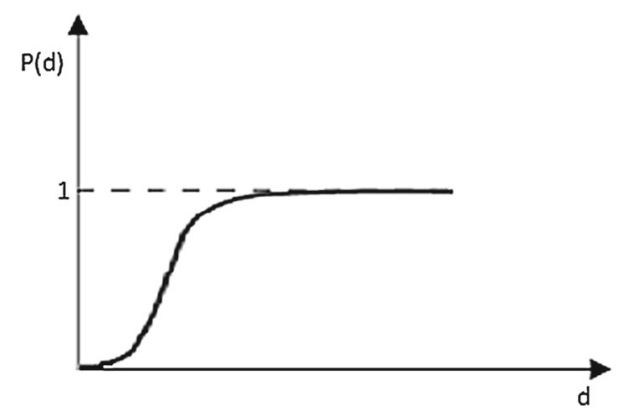

Fig. 3 Gaussian preference function

The weights $w_{i}$ represent the relative importance of each criterion in the decision.

As each action is compared with the other $n-1$ actions, the two following preference flows are defined:

- Positive flow

$$
\Phi^{+}(a)=\frac{1}{n-1} \sum_{x \in A}^{\pi}(a, x) .
$$

where $n$ is the number of actions in set $A$.

This score represents the global strength of action $a$ relative to all the other actions and the aim is to maximise it.

- Negative flow

$$
\Phi^{-}(a)=\frac{1}{n-1} \sum_{x \in A}^{\pi}(x, a) .
$$


This score represents the global weakness of $a$ relative to all the other actions and the aim is to minimise it.

The net flow is the balance between the two previous flows and is given by:

$\Phi(a)=\Phi^{+}(a)-\Phi^{-}(a)$.

The positive and negative flows are used to build the PROMETHEE I partial ranking, whilst the net flow is the basis for the PROMETHEE II complete ranking: all the actions can be ranked in order of net flow value.

As PPA is based on PROMETHEE, it inherits its advantages. In particular, weights and preference functions can be assigned to criteria. If the criteria weights are known $a$ priori by the decision-maker, this is important information which should be added to the model. Applying a preference function can also result in better representation of reality because changes in inputs (resources) and outputs (production) do not always have a linear effect on productivity. An increase in facility spending of 1000 Euros on an existing 10,000 Euro bill does not necessarily have the same effect as an increase of 1000 Euros on a 1000,000 Euro bill. Furthermore, in PROMTHEE all criteria can be expressed in their own units and thus there is no scaling effect. No normalisation of the scores is required, which avoids the drawback of the ranking depending on the choice of normalisation method (Tofallis 2008; Ishizaka and Nemery 2011). A detailed, technical discussion of the normalisation effect in the specific case of universities is given in Tofallis (2012).

\subsection{Productivity measurement}

The interpretation of net flows in PPA depends on the set of output and input criteria used. The higher the net flows of an action's outputs and the lower the net flows of its inputs, the better it is.

In order to evaluate performances on the basis of the net flows of outputs and inputs, we define the PPA production possibility set $\left(\Psi_{\mathrm{PPA}}\right)$ as:

$$
\begin{aligned}
\Psi_{\mathrm{PPA}} & =\left\{\left(\Phi_{\mathrm{I}}, \Phi_{\mathrm{O}}\right) \in R^{2} \mid \Phi_{\mathrm{O}} \leq \sum_{i=1}^{n} \gamma_{i} \Phi_{\mathrm{O} i} ; \Phi_{\mathrm{I}}\right. \\
& \left.\geq \sum_{i=1}^{n} \gamma_{i} \Phi_{\mathrm{I} i} ; \sum_{i=1}^{n} \gamma_{i}=1 ; \gamma_{i} \geq 0, i=1, \ldots, n\right\} .
\end{aligned}
$$

where $\Phi_{\mathrm{I}}$ is the net input flow, and $\Phi_{\mathrm{O}}$ is the net output flow.

In line with the DEA variable return to scale production possibility set (Banker et al. 1984) we assume that (Cooper et al. 2004, p 42):

1. All observed activities $\left(\Phi_{\mathrm{I} i}, \Phi_{\mathrm{O} i}\right)(i=1, \ldots, n)$ belong to $\Psi_{\mathrm{PEA}}$;
2. For an activity $\left(\Phi_{\mathrm{I}}, \Phi_{\mathrm{O}}\right)$ in $\Psi_{\mathrm{PPA}}$, any activity $\left(\overline{\Phi_{\mathrm{I}}}, \overline{\Phi_{\mathrm{O}}}\right)$ with $\overline{\Phi_{\mathrm{I}}}>\Phi_{\mathrm{I}}$ and $\overline{\Phi_{\mathrm{O}}}<\Phi_{\mathrm{O}}$ is included in $\Psi_{\mathrm{PEA}}$. That is, any activity with net input flow of not less than $\Phi_{\mathrm{I}}$ and net output flow no greater than $\Phi_{\mathrm{O}}$ is feasible.

3. Any semi-positive convex linear combination of activities in $\Psi_{\mathrm{PPA}}$ belongs to $\Psi_{\mathrm{PPA}}$.

The production possibility set is a polyhedral convex set whose vertices correspond to all the actions that are not dominated by another action, i.e. no action simultaneously has higher net output flow and lower net input flow. The PPA frontier can easily be represented graphically (Sect. 2.4).

It worth noting that, unlike the original DEA (Charnes et al. 1978; Banker et al. 1984), inputs and outputs are not explicitly considered in the production possibility set (5). Similar approaches can be found in more recent DEA applications. One of the most popular of these approaches is PCA-DEA (see Ueda and Hoshiai 1997; Adler and Golany 2001, 2002; Adler and Yazhemsky 2010), in which DEA is used on the Principal Components of the original variables.

A second difference from the original DEA is that if one action changes its inputs and outputs, it can modify the inputs and outputs of other actions in the production possibility set (5). This feature is also displayed in other DEA model, for example by the model of Muñiz (2002), in which indexes of efficiency obtained by DEA in the first stage are used as inputs in the second stage. Other examples of DEA models sharing this feature are all the DEA applications on data pre-treated with specific normalisations (such as max-min, Nardo et al. 2008), for instance the model used in Mizobuchi (2014).

To measure the distance to the frontier in PPA, we use an algorithm based on the standard additive model introduced by Charnes et al. (1985) and elaborated by Banker et al. (1989). The algorithm is based on two steps. The first step measures the input distance as:

$$
\begin{aligned}
& \max \Delta_{\boldsymbol{\Phi}_{\boldsymbol{I}} \boldsymbol{k}} \\
& \boldsymbol{\Phi}_{\boldsymbol{I}_{\boldsymbol{k}}}=\sum_{j=1}^{\boldsymbol{n}} \boldsymbol{\Phi}_{\boldsymbol{I}_{j}} \lambda_{j}+\boldsymbol{\Delta}_{\boldsymbol{\Phi}_{\boldsymbol{I} \boldsymbol{k}}} \\
& \boldsymbol{\Phi}_{\boldsymbol{O}_{\boldsymbol{k}}} \leq \sum_{j=1}^{\boldsymbol{n}} \boldsymbol{\Phi}_{\boldsymbol{O}_{j}} \lambda_{\boldsymbol{j}} \\
& \sum_{\boldsymbol{j}=1}^{\boldsymbol{n}} \lambda_{\boldsymbol{j}}=1 \\
& \lambda_{\boldsymbol{j}} \geq 0 ; \boldsymbol{j}=1, \ldots, \boldsymbol{n} \\
& \boldsymbol{\Delta}_{\boldsymbol{\Phi}_{\boldsymbol{I}} \boldsymbol{k}} \geq 0 .
\end{aligned}
$$

where $\Delta_{\Phi_{I k}}$ is the input distance to the frontier for the actions $k$ under evaluation;

$\Phi_{\mathrm{I}_{k}}$ is the net output flow of action $k$ in the evaluation; 
$\Phi_{\mathrm{O}_{k}}$ is the net output flow of action $k$ in the evaluation; $\lambda_{j}$ is one element of the intensity vector.

In the second step we measure the output distance as:

$$
\begin{aligned}
& \max \boldsymbol{\Delta}_{\boldsymbol{\Phi}_{\boldsymbol{O}_{\boldsymbol{k}}}} \\
& \boldsymbol{\Phi}_{\boldsymbol{I}_{\boldsymbol{k}}} \geq \sum_{\boldsymbol{j}=1}^{\boldsymbol{j}} \boldsymbol{\Phi}_{\boldsymbol{I}_{j}} \lambda_{j} \\
& \boldsymbol{\Phi}_{\boldsymbol{O}_{\boldsymbol{k}}}=\sum_{\boldsymbol{j}=1}^{\boldsymbol{n}} \boldsymbol{\Phi}_{\boldsymbol{O}_{j}} \lambda_{\boldsymbol{j}}-\boldsymbol{\Delta}_{\boldsymbol{\Phi}_{\boldsymbol{O}} \boldsymbol{k}} \\
& \sum_{\boldsymbol{j}=1}^{\boldsymbol{n}} \lambda_{\boldsymbol{j}}=1 \\
& \boldsymbol{\lambda}_{\boldsymbol{j}} \geq 0 ; \boldsymbol{j}=1, \ldots, \boldsymbol{n} \\
& \boldsymbol{\Delta}_{\boldsymbol{V}} \boldsymbol{O}_{\boldsymbol{k}} \geq 0 .
\end{aligned}
$$

where $\boldsymbol{\Delta}_{\Phi_{\mathrm{O} k}}$ is the output distance to the frontier for the actions $k$ under evaluation.

Finally, the minimum distance to the frontier defines the PPA inefficiency as:

$$
\min \Delta=\min \left[\boldsymbol{\Delta}_{\Phi_{\mathrm{I} k}}, \boldsymbol{\Delta}_{\Phi_{\mathrm{O} k}}\right]
$$

\subsection{PPA frontier visualisation}

The productivity of the actions can be depicted in a twodimensional graph (Fig. 4). The range of the two axes is -1 to 1 , and they represent the net flows of the inputs and outputs. Four categories of action can be defined:

Efficient This type of action produces a high output (i.e. high net output flow) with a low input (i.e. low net input flow). Thus efficient actions appear in the top-left quadrant of the graph (e.g. actions $B$ and $C$ in Fig. 4).

Effective This type of action is defined solely in terms of its outputs (high) and thus appears in the topright quadrant (e.g. actions $D$ and $E$ in Fig. 4).

Frugal This type of action minimises spending and is represented by the bottom-left quadrant (e.g. $A$ in Fig. 4).

Inefficient This type of action has high inputs and low outputs and sits in bottom-right quadrant (e.g. $G$ in Fig. 4).

Any action that is not dominated in terms of Input/Output net flows lies on the PPA frontier (shown in red on Fig. 4). Actions that are not on the frontier can be improved by taking real action(s) that are closest to the frontier as an example (e.g. in Fig. 4 action F can be improved by looking at the example of action $\mathrm{C}$ ).
An action's productivity ranking is determined by measuring the distance between it and the productivity frontier. This distance can be measured in various ways, e.g.:

- Horizontally, on the input axis (x), by programme (6): the input orientation assumes a given output level and searches for improvements in inputs that will bring the action closer to the PPA frontier.

- Vertically, on the output axis (y), by programme (7): the output orientation assumes a given level of inputs and searches for improvements in outputs that will bring the action closer to the PPA frontier.

- Along both axes simultaneously: if the decision-maker is not facing any constraints and has the control over both inputs and outputs, the orientation will depend on his/her objectives. For instance, by choosing the minimum between the two previous measures (8), this shows how an action can be efficient when either input or output values are adjusted.

PPA has been implemented in two stages analysis:

1. The input and output net flows have been estimated by Visual PROMETHEE software (http://www.prometheegaia.net/software.html), which is free to academics.

2. In order to estimate the output and input distance to the frontier with programme (6) and programme (7), an optimisation code in R has been developed and can be forwarded on request.

\section{Case study}

\subsection{Introduction}

Measuring universities' performance is a fundamental necessity for society as it shows how well taxpayers' money is being used, but it is not an easy task. The productive process of a university is a complex, multi-dimensional system with more than one objective (Agasisti and Haelermans 2016). Recently globalisation has increased the pressure on universities to improve their standards (Steiner et al. 2013). Performance measures have a significant impact on universities' ability to attract the top scholars, bright students and research funding (Kaycheng 2015).

Comparisons of the quality of universities are regularly published in the form of ranking lists. Some UK examples are The Complete University Guide, The Guardian University Guide and the Sunday Times University Guide, all of which include leagues tables based on publicly available statistical data, e.g. from the Higher Education Statistical Agency (HESA) and the National Student Survey (NSS). These rankings have a sizeable impact on universities as they are one 
Fig. 4 PPA frontier graph (colour figure online)

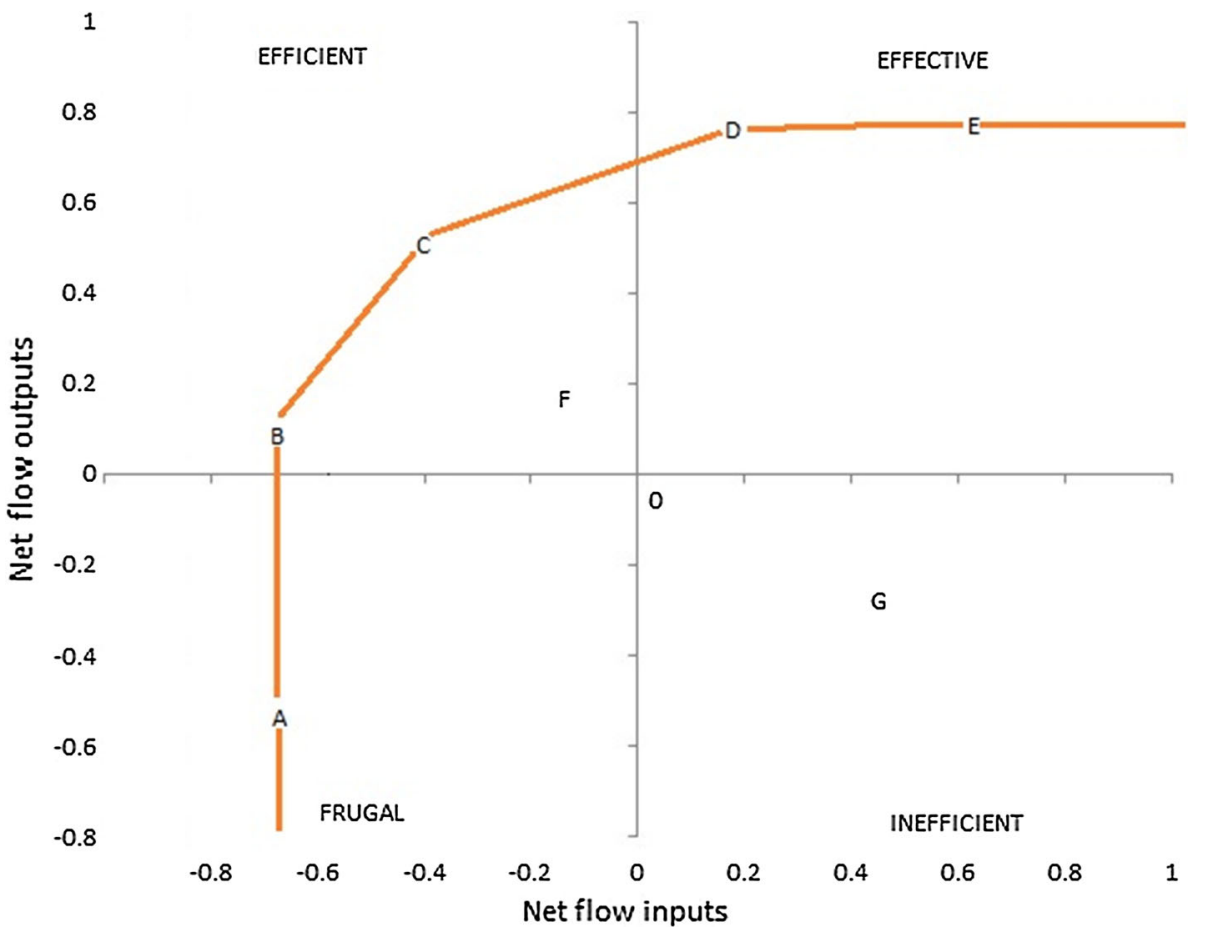

indication of prestige and have a direct influence on the number and quality of applicants (Hazelkorn 2007). As published rankings have proliferated so have criticisms of them (Yorke 1997; Bowden 2000; Oswald 2001; Vaughn 2002; Marginson 2007; Taylor and Braddock 2007; Tofallis 2012; De Witte and Hudrlikova 2013). The method used to rank universities is usually a simple weighted sum of the evaluation criteria, where the aggregation is fully compensatory and does not differentiate between universities with strengths in different areas. Moreover, as each criterion is measured in a different unit, the values need to be transformed into equivalent units to enable them to be summed. There are numerous ways of standardising data (commercial rankings generally uses $z$-transformation), and they often lead to different final rankings (Pomerol and Barba-Romero 2000). To avoid these problems, Giannoulis and Ishizaka (2010) used an outranking method. Another criticism is that input and output data are treated in the same way, which rewards inefficiency (Bougnol and Dulá 2015). For example, consider two universities with exactly the same input and output levels. The following year one of them reduces its input (e.g. facilities spend), but they continue to have the same output. The published lists will assign a lower ranking to the one which has decreased its input, although it has become more efficient. It would therefore be wise in the MCDA methodology to minimise input data and to maximise output data. Universities are facing funding cuts, so their input resources are becoming more restricted and therefore productivity is crucial. This means that efficiency should be considered alongside rankings based on various measures of perceived quality.

\subsection{Description of data}

The data used in the analysis were obtained from the Sunday Times University Guide 2014 (http://www.thesundaytimes. co.uk/sto/University_Guide/). It evaluated British universities on the basis of nine criteria (Table 1).

Two of the criteria in Table 1 can be used as proxy of the two standard factors of production: capital ("Services/facilities spent") and labour ("Staff"). As shown in several analysis of efficiency in Higher Education sector (among others see Thanassoulis et al. 2011) the "production" of university is multi-dimensional and often intangible. This is the reason why not only quantitative, but also qualitative measure of production should be taken into account. Based on this framework "The total number of students" can be used as a proxy of quantity production, and the remaining six criteria can be used as proxies of quality of production ("Student satisfaction", "Research quality", "UCAS entry points", "Graduate prospects", "Firsts/2:1s", and "Completion rate").

From a technical perspective, several of these criteria are scale-independent. Figure 5 shows the universities' production process based on Table 1 variables. In our case, the universities use one scale-dependent and one scaleindependent input to produce one scale-dependent and six scale-independent outputs.

Scale independence is not a problem in PPA as the preference function transforms all differences to a 1 to -1 scale. In this case study $\mathrm{V}$-shape preference functions have been selected as all criteria are numerical. The preference thresholds have been chosen proportionally to the standard 
Table 1 Evaluation criteria; abbreviations in parentheses are used hereafter

Fig. 5 University production process

\begin{tabular}{ll}
\hline Criteria & Description \\
\hline $\begin{array}{l}\text { Student satisfaction } \\
\text { (StSat) }\end{array}$ & $\begin{array}{c}\text { Students' evaluation of teaching quality; taken from the 2013 National } \\
\text { Student Survey, a survey of final-year students }\end{array}$ \\
$\begin{array}{l}\text { Research quality } \\
\text { (ResQual) }\end{array}$ & $\begin{array}{c}\text { The average quality of the research undertaken; based on the 2008 Research } \\
\text { Assessment Exercise }\end{array}$ \\
UCAS entry points (Ucas) & $\begin{array}{c}\text { The average Universities and Colleges Admissions Service (UCAS) tariff } \\
\text { score for new students }\end{array}$ \\
Graduate prospects & $\begin{array}{c}\text { The number of graduates entering employment (only roles typically filled by } \\
\text { (GrdProsp) } \\
\text { graduates were included) or further study, divided by the total number of }\end{array}$ \\
Firsts/2:1s (1-2:1s) & graduates with a known destination, expressed as a percentage \\
& $\begin{array}{c}\text { The percentage of graduates achieving a first (70\%) or upper second (60\%) } \\
\text { class honours degree }\end{array}$ \\
Completion rate (Compl) & $\begin{array}{c}\text { The proportion of students completing their course } \\
\text { Staff (Staff) }\end{array}$ \\
The total number of academic staff \\
Services/facilities spent \\
(ServSp)
\end{tabular}$\quad \begin{aligned} & \text { The total number of students } \\
& \text { Spend per student on academic services (books, journals, staff, computer } \\
& \text { hardware and software, but not buildings) and student facilities (sports, } \\
& \text { careers services, health, counselling, etc). Expenditure was averaged over } \\
& \text { three years to allow for uneven expenditure }\end{aligned}$

deviation observed on each criterion. This is a statistical approach which is consistent with the normalisation $(z-$ transformation) used in the Sunday Times analysis. Of course other choices could be made taking into account the preferences of evaluators. The weights of the criteria are the same as in the Sunday Times university ranking, i.e. 1.5 for student satisfaction and research quality, 1 for all other criteria. In the analysis, the criterion "student-staff ratio" has been replaced by two separate criteria: the numbers of students (an output) and staff (an input) as suggested by (Thanassoulis et al. 1995).

Table 2 summarises the data. The last two columns show that some universities perform well in terms of the scaleindependent outputs (Bath, Cambridge, Imperial College and Oxford). Some universities do best in terms of the scaledependent output (Manchester). Finally, some of the small universities are best at keeping their costs low (Highlands and Islands, London Metropolitan).

\subsection{Results}

In order to measure the universities' productivity, we used the algorithms presented in Sects. 2.2 and 2.3. In particular, we first estimate the input and output net flows by Promethee, and then we measure inefficiencies by means of Eqs. (6), (7), and (8). Four universities are on the PPA frontier (i.e. $\boldsymbol{\Delta}_{\Phi_{\mathrm{I}}}=$ $\boldsymbol{\Delta}_{\Phi_{\mathrm{I}}}=0$ ): two of them are old universities, Cambridge and Bath, and two of them are among the most recent universities,
Bishop Grosseteste and Arts Bournemouth. The distance to PPA frontier (Sect. 2.4) can be interpreted as the amount of potential improvement. Table 3 in Appendices summarises the results: $\boldsymbol{\Delta}_{\Phi_{\mathrm{I}}}$ is the inefficiency inputs, $\boldsymbol{\Delta}_{\Phi_{\mathrm{O}}}$ represents the inefficiency outputs and $\min \Delta$ is the minimum distance to the frontier defined by the four efficient universities.

As Table 3 in Appendices is difficult to read, the PPA method allows for an intuitive, visual representation of the results, this highlights unexpected relationships that might lead to important insights.

Higher education institutions vary considerably in history, objectives and operating practices (Shattock 2013). For our analysis we separated universities into three groups:

- The old universities, also called traditional or pre-1992 universities (black rhombuses);

- The new universities, also called modern universities or post-1992 universities. These are polytechnics that acquired university status in 1992 (grey triangles);

- The new-new universities. Post-1992 universities that are not former polytechnics (black circles).

The red line in Fig. 6 represents the PPA frontier. We have used the same criterion weights as Sunday Times university ranking, i.e. 1.5 for student satisfaction and research quality, 1 for all other criteria. Only the best actions are on the frontier (Cambridge, Bath, Bishop Grosseteste and Arts Bournemouth). It is interesting to note that the new-new uni- 
Table 2 Descriptive statistic

\begin{tabular}{lllll}
\hline & Average & SD & Max & Min \\
\hline (I) Staff & 1380 & 1100 & Oxford & Highlands and Islands \\
(I) ServSp & 1520 & 500 & Oxford & London Metropolitan \\
(O) StSat & 81.25 & 3.03 & Bath & London Metropolitan \\
(O) ResQual & 12.07 & 11.32 & Cambridge & Worcester \\
(O) Ucas & 354.85 & 84.20 & Cambridge & Bedfordshire \\
(O) GrdProsp & 64.72 & 10.18 & Imperial College & Buckinghamshire New \\
(O) $1-2: 1 \mathrm{~s}$ & 66.18 & 10.14 & Oxford & Buckinghamshire New \\
(O) Compl & 85.87 & 7.22 & Cambridge & East London \\
(O) Students & 17210 & 7880 & Manchester & Bishop Grosseteste \\
\hline
\end{tabular}

Fig. 6 PPA frontier (colour figure online)

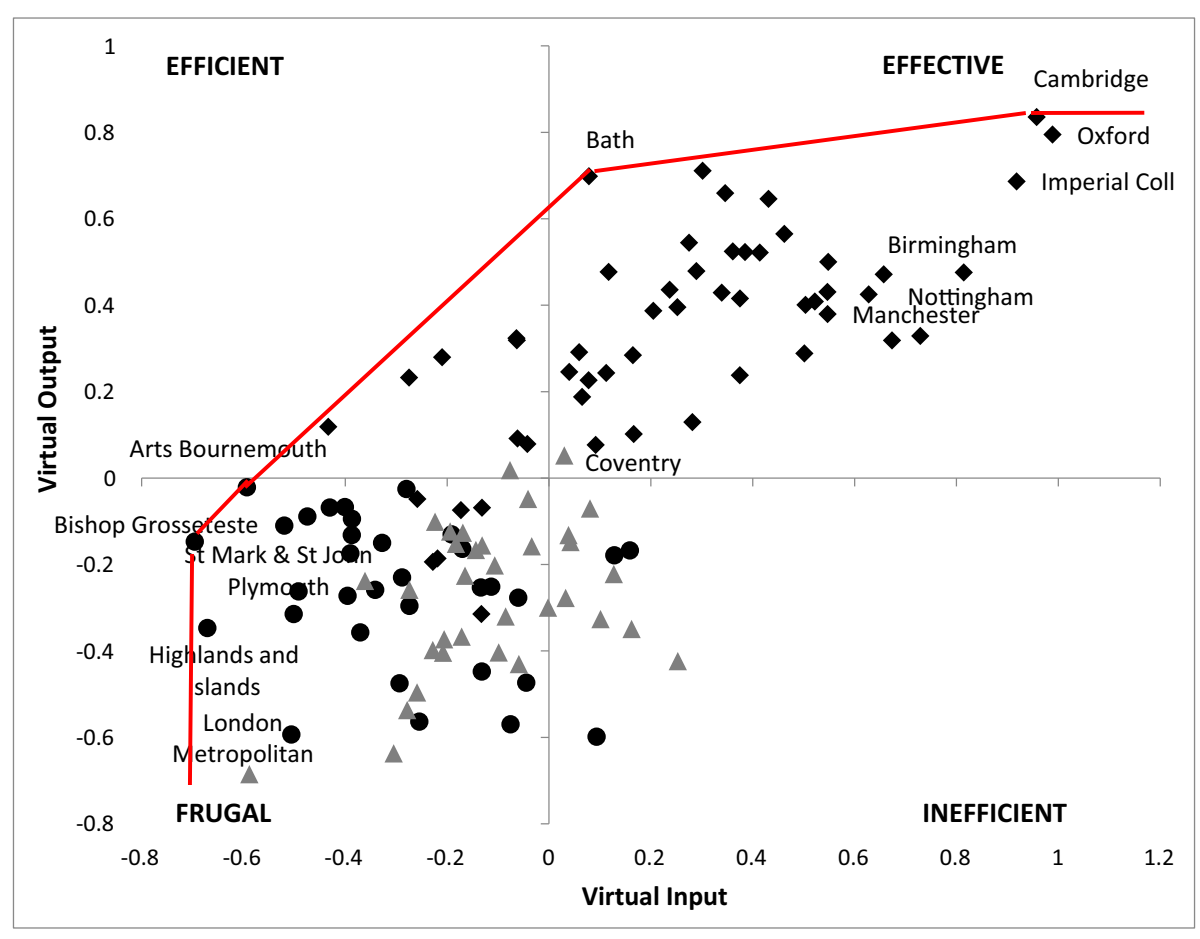

- Old universities

A New universities

- New new universities versities are generally located on the bottom left: they use a frugal production system. None of post-1992 universities have a positive net flow; they are not effective. None of the old universities are in the worst quadrant (bottom-right). The former polytechnics are generally located towards the bottom right and thus are generally less efficient than the other universities. A clear exception is London Metropolitan University whose position suggests that its working practices are much closer to those of the new-new universities.

In policy terms, effectiveness is expensive and requires long-term strategies; however, effectiveness is the only guarantee of the prestige that allows an institution last more than a single generation (Huisman et al. 2012; Middlehurst 2013; Filippakou and Tapper 2015). In conflicts with other authorities it is only the quality of their achievements that has enabled universities to maintain their position (Lenartowicz 2015). Moreover, in the recursive production of themselves, universities have specialised in two basic activities: research and education of students. Both are 'axes of construction' for self-reproduction. What is new today will be known tomorrow and will form the basis for further discoveries. Similarly, today's students will be tomorrow's teachers.

\subsection{Comparison of the results with the traditional DEA}

\subsubsection{The role of scale-independent and scale-dependent variables}

In order to clarify the strong points of PPA, we compared our results with those of a DEA efficiency analysis. A graphical 
comparison cannot be done as it is not possible for DEA to have a multi-dimensional representation. It is worth noting that a DEA evaluation of performance based on the data presented in Table 1 does not make much sense as data are a mixture of scale-independent (ratios and indices) and scaledependent variables (Fig. 5). Because of this we modified the data before proceeding with the DEA analysis. We used Dyson et al.'s (2001) procedure, which is as follows: we multiplied ServSp, StSat, Ucas, GrdProsp, 1-2:1s and Compl by the number of students and we multiplied ResQual by the number of academic staff. These transformations allowed us to avoid the problems with DEA described by (Dyson et al. 2001; Cooper et al. 2007; Cook et al. 2014). There is, however, the drawback that the rankings depend on the variables by which the ratio and index variables were multiplied (Tofallis 2012). This problem does not appear with the PPA.

\subsubsection{Selectivity power}

In this analysis, we use the standard input-oriented DEA model and we assume variable return to scale (Banker et al. 1984). The efficiency indices estimated by DEA are given in the sixth column in Table 3 . In order to compare the PPA inefficiency (ranging from 0 to 2 ) with the DEA efficiency (ranging from 0 to 1 ) indices, we transformed $\min \Delta$ as follows:

$\mathrm{EFF}_{\mathrm{PPA}}=\frac{(2-\min \Delta)}{2}$

In this case EFFPPA is in the interval $[0,1]$ as the DEA efficiency index. The last column in Table 3 shows the difference between $\mathrm{EFF}_{\mathrm{PPA}}$ and $\mathrm{EFF}_{\mathrm{DEA}}$. As the DEA analysis places more universities on the efficient frontier it is less selective than PPA. Under DEA 22 universities are fully efficient, they are: Sheffield Hallam, Manchester Metropolitan, West of England, Northumbria, Plymouth, Coventry, Strathclyde, Manchester, Queen Margaret Edinburgh, Bangor, Nottingham, University College London, Cardiff, Leeds, Birmingham, Warwick, London Metropolitan, Oxford, Highlands and Islands, Bishop Grosseteste, Cambridge and Teesside. Only two of those universities are also efficient under PPA, Bishop Grosseteste and Cambridge. Two universities (Bath and Arts Bournemouth) are efficient under PPA but not DEA.

\subsubsection{External information and preferences}

The efficiency difference is due to the main difference between DEA and PPA, which is the decision-maker's role in the evaluation. The results of DEA are entirely data driven. However, in some case, information is available due to the decision-maker expertise. Therefore, weights restriction are entered in the system (Podinovski 2016). In the PPA, we have another scenario, where the decision-maker has a good idea of the preference function and weight of each criterion. Depending on the problem and information available, decision-maker can choose to use DEA (no or few information available) or the PPA (good information inducing clear preference functions and weights).

\subsubsection{Relative measures}

PPA uses relative measures as in PROMETHEE. This means that if the performance (in input or output) of one action is modified, the relative performance of all others actions are also modified. This is because, if one alternative change its inputs and outputs, such a change modifies the input and output net flows of all the other units. This characteristic is different from the DEA, where the performance of DMUs is modified only if the performance of DMUs on the frontier is modified. Therefore, PPA takes into account the global situation (not only as regards to DMUs on the frontier) to calculate the performance of actions.

\section{Conclusions}

New technologies have allowed large volumes of data to be stored and transferred rapidly across large distances. The final challenge is working out how to extract and deliver information from this vast amount of data. An overload of mismanaged information can lead to disagreements, stress, waste and poor performance. In this paper, we have described an adaptation of PROMETHEE for productivity analysis problems and communicated the results in a graph that makes it easy to distinguish between efficient, effective, frugal and ineffective actions. This visual tool gives a holistic view of the results and makes it easy to identify unexpected relationships as well as increasing the transparency of the analysis. It supports the justification of suggestions for improvements. Evidence-based visual management creates a sense of openness and objectivity, which is a precondition for developing employees' trust in management. PPA is an extension of PROMETHEE and therefore inherits its advantages. It does not require any standardisation; in contrast standardisation is a widespread problem in MCDA methods, which require the analyst to begin by standardising raw data in different units to make them comparable. There are several standardisation methods that produce different results. Avoiding the need for standardisation removes this problem. PPA uses a partial compensatory approach: a bad score cannot be compensated for (as in the full-aggregation MCDA methods) or ignored (as in the traditional DEA). A preference function and a weight can be defined for each criterion.

To illustrate the method, we analysed the performance of British universities. The task of universities is to generate, acquire and transfer knowledge. They are an important component of the economy. University rankings are attracting more attention than ever. Many universities clearly state their 
ranking objective (e.g. be among the top 20 universities) in their strategic plan. At the same time, economical sustainability is a major issue, because public funding for universities is decreasing. As universities face the challenge of doing more with less, improving productivity becomes vital. In our case study, PPA highlighted the wide differences in the productivity of British universities. Overall, new and the most recent universities tend to be more interested in keeping costs down, whereas old universities tend to be more effective. The PPA is a tool that can be used to inform decision-makers about best practice, based on easy-to-interpret information. To improve their position universities can look at peers on the PPA frontier. This kind of benchmarking scheme can be used by university management to identify ways to improve relative performance. The graphical representation of results clearly illustrates an institution's position relative to its competitors. It is important to note, however, that productivity evaluation is only a first step in the process of reflection on performance. It gives some indication of which variables need to be improved, but the determining the operational changes required to do this can be very complex. For example, reducing spending on staff and services will reduce input, but may also have a negative impact on the output variables if working practices are not adjusted.

Finally, as the PPA is a generic method, implemented in a free accessible tool, we expect that in future research it will be applied to a wide range of industrial and public problems.

\section{Compliance with ethical standards}

Conflict of interest All authors declare that there is no conflict of interest.

Human participants or animals This article does not contain any studies with human participants or animals performed by any of the authors.

Open Access This article is distributed under the terms of the Creative Commons Attribution 4.0 International License (http://creativecomm ons.org/licenses/by/4.0/), which permits unrestricted use, distribution, and reproduction in any medium, provided you give appropriate credit to the original author(s) and the source, provide a link to the Creative Commons license, and indicate if changes were made.

\section{Appendix}

Table 3 Results

\begin{tabular}{|c|c|c|c|c|c|c|}
\hline University & $\Delta_{\Phi_{\mathrm{I}}}$ & $\boldsymbol{\Delta}_{\Phi_{\mathrm{O}}}$ & $\operatorname{Min} \Delta$ & EFFPPA $_{\text {PPA }}$ & $\mathrm{EFF}_{\mathrm{DEA}}$ & $\mathrm{EFF}_{\mathrm{DEA}}-\mathrm{EFF}_{\mathrm{PPA}}$ \\
\hline Aberdeen & 0.46 & 0.46 & 0.46 & 0.77 & 0.84 & 0.07 \\
\hline Abertay Dundee & 0.32 & 0.57 & 0.32 & 0.84 & 0.61 & -0.23 \\
\hline Aberystwyth & 0.47 & 0.56 & 0.47 & 0.77 & 0.86 & 0.09 \\
\hline Anglia Ruskin & 0.47 & 0.77 & 0.47 & 0.77 & 0.83 & 0.07 \\
\hline Arts Bournemouth & 0.00 & 0.00 & 0.00 & 1.00 & 0.84 & -0.16 \\
\hline Arts London & 0.85 & 0.88 & 0.85 & 0.58 & 0.81 & 0.24 \\
\hline Aston Birmingham & 0.21 & 0.23 & 0.21 & 0.90 & 0.69 & -0.21 \\
\hline Bangor & 0.36 & 0.39 & 0.36 & 0.82 & 1.00 & 0.18 \\
\hline Bath & 0.00 & 0.00 & 0.00 & 1.00 & 0.96 & -0.04 \\
\hline Bath Spa & 0.17 & 0.19 & 0.17 & 0.92 & 0.69 & -0.22 \\
\hline Bedfordshire & 0.62 & 1.10 & 0.62 & 0.69 & 0.86 & 0.17 \\
\hline Birmingham & 0.79 & 0.32 & 0.32 & 0.84 & 1.00 & 0.16 \\
\hline Birmingham City & 0.69 & 0.91 & 0.69 & 0.66 & 0.73 & 0.08 \\
\hline Bishop Grosseteste & 0.00 & 0.00 & 0.00 & 1.00 & 1.00 & 0.00 \\
\hline Bolton & 0.19 & 0.67 & 0.19 & 0.91 & 0.63 & -0.27 \\
\hline Bournemouth & 0.51 & 0.57 & 0.51 & 0.75 & 0.87 & 0.13 \\
\hline Bradford & 0.48 & 0.57 & 0.48 & 0.76 & 0.80 & 0.04 \\
\hline Brighton & 0.48 & 0.53 & 0.48 & 0.76 & 0.92 & 0.16 \\
\hline Bristol & 0.65 & 0.27 & 0.27 & 0.87 & 0.91 & 0.04 \\
\hline Brunel & 0.59 & 0.62 & 0.59 & 0.71 & 0.68 & -0.02 \\
\hline Buckinghamshire New & 0.79 & 1.30 & 0.79 & 0.61 & 0.39 & -0.22 \\
\hline Cambridge & 0.00 & 0.00 & 0.00 & 1.00 & 1.00 & 0.00 \\
\hline Canterbury Christ Church & 0.35 & 0.51 & 0.35 & 0.83 & 0.95 & 0.13 \\
\hline Cardiff & 0.46 & 0.33 & 0.33 & 0.84 & 1.00 & 0.17 \\
\hline Cardiff Metropolitan & 0.41 & 0.54 & 0.41 & 0.80 & 0.65 & -0.15 \\
\hline
\end{tabular}


Table 3 continued

\begin{tabular}{|c|c|c|c|c|c|c|}
\hline University & $\Delta_{\Phi_{I}}$ & $\boldsymbol{\Delta}_{\Phi_{\mathrm{O}}}$ & $\operatorname{Min} \Delta$ & $\mathrm{EFF}_{\mathrm{PPA}}$ & $\mathrm{EFF}_{\mathrm{DEA}}$ & $\mathrm{EFF}_{\mathrm{DEA}}-\mathrm{EFF}_{\mathrm{PPA}}$ \\
\hline Central Lancashire & 0.80 & 1.03 & 0.80 & 0.60 & 0.85 & 0.25 \\
\hline Chester & 0.49 & 0.54 & 0.49 & 0.76 & 0.76 & 0.00 \\
\hline Chichester & 0.30 & 0.33 & 0.30 & 0.85 & 0.50 & -0.35 \\
\hline City & 0.73 & 0.60 & 0.60 & 0.70 & 0.65 & -0.05 \\
\hline Coventry & 0.55 & 0.59 & 0.55 & 0.73 & 1.00 & 0.28 \\
\hline Creative Arts & 0.65 & 1.04 & 0.65 & 0.68 & 0.35 & -0.33 \\
\hline Cumbria & 0.20 & 0.35 & 0.20 & 0.90 & 0.75 & -0.15 \\
\hline De Montfort & 0.53 & 0.66 & 0.53 & 0.74 & 0.78 & 0.04 \\
\hline Derby & 0.56 & 0.72 & 0.56 & 0.72 & 0.56 & -0.16 \\
\hline Dundee & 0.43 & 0.46 & 0.43 & 0.79 & 0.82 & 0.04 \\
\hline Durham & 0.40 & 0.11 & 0.11 & 0.95 & 0.89 & -0.06 \\
\hline East Anglia & 0.51 & 0.31 & 0.31 & 0.85 & 0.75 & -0.09 \\
\hline East London & 0.39 & 0.92 & 0.39 & 0.81 & 0.85 & 0.04 \\
\hline Edge Hill & 0.53 & 0.60 & 0.53 & 0.74 & 0.77 & 0.04 \\
\hline Edinburgh & 1.00 & 0.47 & 0.47 & 0.77 & 0.99 & 0.22 \\
\hline Edinburgh Napier & 0.33 & 0.47 & 0.33 & 0.84 & 0.73 & -0.11 \\
\hline Essex & 0.64 & 0.61 & 0.61 & 0.70 & 0.72 & 0.03 \\
\hline Exeter & 0.30 & 0.08 & 0.08 & 0.96 & 0.91 & -0.05 \\
\hline Falmouth & 0.64 & 0.83 & 0.64 & 0.68 & 0.41 & -0.27 \\
\hline Glasgow & 0.80 & 0.36 & 0.36 & 0.82 & 0.85 & 0.03 \\
\hline Glasgow Caledonian & 0.59 & 0.70 & 0.59 & 0.71 & 0.77 & 0.07 \\
\hline Gloucestershire & 0.42 & 0.62 & 0.42 & 0.79 & 0.50 & -0.29 \\
\hline Glyndwr & 0.56 & 0.92 & 0.56 & 0.72 & 0.50 & -0.22 \\
\hline Goldsmiths, London & 0.03 & 0.03 & 0.03 & 0.99 & 0.96 & -0.02 \\
\hline Greenwich & 0.61 & 0.84 & 0.61 & 0.70 & 0.84 & 0.14 \\
\hline Harper Adams & 0.20 & 0.22 & 0.20 & 0.90 & 0.71 & -0.19 \\
\hline Heriot-Watt & 0.10 & 0.11 & 0.10 & 0.95 & 0.90 & -0.05 \\
\hline Hertfordshire & 0.86 & 1.06 & 0.86 & 0.57 & 0.69 & 0.12 \\
\hline Highlands and Islands & 0.02 & 0.23 & 0.02 & 0.99 & 1.00 & 0.01 \\
\hline Huddersfield & 0.51 & 0.56 & 0.51 & 0.75 & 0.86 & 0.12 \\
\hline Hull & 0.50 & 0.54 & 0.50 & 0.75 & 0.82 & 0.07 \\
\hline Imperial Coll & 0.85 & 0.14 & 0.14 & 0.93 & 0.81 & -0.12 \\
\hline Keele & 0.08 & 0.09 & 0.08 & 0.96 & 0.75 & -0.21 \\
\hline Kent & 0.38 & 0.41 & 0.38 & 0.81 & 0.85 & 0.04 \\
\hline King's Coll & 0.95 & 0.47 & 0.47 & 0.77 & 0.83 & 0.07 \\
\hline Kingston & 0.64 & 0.98 & 0.64 & 0.68 & 0.88 & 0.20 \\
\hline L.S.E. & 0.51 & 0.19 & 0.19 & 0.91 & 0.90 & -0.01 \\
\hline Lancaster & 0.25 & 0.23 & 0.23 & 0.89 & 0.87 & -0.02 \\
\hline Leeds & 0.56 & 0.33 & 0.33 & 0.84 & 1.00 & 0.17 \\
\hline Leeds Beckett & 0.52 & 0.80 & 0.52 & 0.74 & 0.96 & 0.22 \\
\hline Leeds Trinity & 0.19 & 0.39 & 0.19 & 0.91 & 0.73 & -0.17 \\
\hline Leicester & 0.70 & 0.36 & 0.36 & 0.82 & 0.67 & -0.15 \\
\hline Lincoln & 0.43 & 0.48 & 0.43 & 0.79 & 0.69 & -0.10 \\
\hline Liverpool & 0.81 & 0.48 & 0.48 & 0.76 & 0.73 & -0.03 \\
\hline Liverpool John Moores & 0.55 & 0.63 & 0.55 & 0.73 & 0.96 & 0.23 \\
\hline London Metropolitan & 0.11 & 0.67 & 0.11 & 0.95 & 1.00 & 0.06 \\
\hline London South Bank & 0.42 & 0.85 & 0.42 & 0.79 & 0.78 & -0.01 \\
\hline Loughborough & 0.40 & 0.29 & 0.29 & 0.86 & 0.81 & -0.04 \\
\hline
\end{tabular}


Table 3 continued

\begin{tabular}{|c|c|c|c|c|c|c|}
\hline University & $\boldsymbol{\Delta}_{\Phi_{\mathrm{I}}}$ & $\boldsymbol{\Delta}_{\Phi_{\mathrm{O}}}$ & $\operatorname{Min} \Delta$ & EFFPPA & $\mathrm{EFF}_{\mathrm{DEA}}$ & $\mathrm{EFF}_{\mathrm{DEA}}-\mathrm{EFF}_{\mathrm{PPA}}$ \\
\hline Manchester & 0.77 & 0.39 & 0.39 & 0.81 & 1.00 & 0.20 \\
\hline Manchester Metropolitan & 0.73 & 0.93 & 0.73 & 0.64 & 1.00 & 0.37 \\
\hline Middlesex & 0.95 & 1.15 & 0.95 & 0.53 & 0.80 & 0.27 \\
\hline Newcastle & 0.47 & 0.22 & 0.22 & 0.89 & 0.84 & -0.05 \\
\hline Newman, Birmingham & 0.31 & 0.37 & 0.31 & 0.85 & 0.59 & -0.25 \\
\hline Northampton & 0.82 & 0.88 & 0.82 & 0.59 & 0.48 & -0.11 \\
\hline Northumbria & 0.66 & 0.74 & 0.66 & 0.67 & 1.00 & 0.33 \\
\hline Nottingham & 0.72 & 0.34 & 0.34 & 0.83 & 1.00 & 0.17 \\
\hline Nottingham Trent & 0.72 & 0.79 & 0.72 & 0.64 & 0.84 & 0.20 \\
\hline Oriental and African Studies & 0.44 & 0.47 & 0.44 & 0.78 & 0.71 & -0.07 \\
\hline Oxford & 0.29 & 0.04 & 0.04 & 0.98 & 1.00 & 0.02 \\
\hline Oxford Brookes & 0.48 & 0.51 & 0.48 & 0.76 & 0.75 & -0.01 \\
\hline Plymouth & 0.56 & 0.63 & 0.56 & 0.72 & 1.00 & 0.28 \\
\hline Portsmouth & 0.57 & 0.62 & 0.57 & 0.72 & 0.85 & 0.14 \\
\hline Queen Margaret Edinburgh & 0.37 & 0.41 & 0.37 & 0.82 & 1.00 & 0.19 \\
\hline Queen Mary, London & 0.73 & 0.51 & 0.51 & 0.75 & 0.73 & -0.02 \\
\hline Queen's, Belfast & 0.42 & 0.33 & 0.33 & 0.84 & 0.85 & 0.01 \\
\hline Reading & 0.36 & 0.39 & 0.36 & 0.82 & 0.79 & -0.03 \\
\hline Robert Gordon & 0.32 & 0.34 & 0.32 & 0.84 & 0.95 & 0.11 \\
\hline Roehampton & 0.58 & 0.74 & 0.58 & 0.71 & 0.47 & -0.24 \\
\hline Royal Holloway, London & 0.21 & 0.22 & 0.21 & 0.90 & 0.86 & -0.04 \\
\hline Salford & 0.56 & 0.79 & 0.56 & 0.72 & 0.69 & -0.03 \\
\hline Sheffield & 0.44 & 0.22 & 0.22 & 0.89 & 0.99 & 0.10 \\
\hline Sheffield Hallam & 0.82 & 0.93 & 0.82 & 0.59 & 1.00 & 0.41 \\
\hline Southampton & 0.71 & 0.36 & 0.36 & 0.82 & 0.82 & 0.00 \\
\hline Southampton Solent & 0.44 & 0.90 & 0.44 & 0.78 & 0.50 & -0.28 \\
\hline St Andrews & 0.14 & 0.02 & 0.02 & 0.99 & 0.80 & -0.19 \\
\hline St Mark and St John, Plymouth & 0.15 & 0.17 & 0.15 & 0.93 & 0.76 & -0.17 \\
\hline Staffordshire & 0.49 & 0.80 & 0.49 & 0.76 & 0.84 & 0.08 \\
\hline Stirling & 0.46 & 0.50 & 0.46 & 0.77 & 0.68 & -0.09 \\
\hline Strathclyde & 0.46 & 0.50 & 0.46 & 0.77 & 1.00 & 0.23 \\
\hline Sunderland & 0.49 & 0.77 & 0.49 & 0.76 & 0.64 & -0.12 \\
\hline Surrey & 0.42 & 0.25 & 0.25 & 0.88 & 0.70 & -0.17 \\
\hline Sussex & 0.47 & 0.43 & 0.43 & 0.79 & 0.80 & 0.02 \\
\hline Swansea & 0.46 & 0.49 & 0.46 & 0.77 & 0.90 & 0.13 \\
\hline Teesside & 0.42 & 0.58 & 0.42 & 0.79 & 1.00 & 0.21 \\
\hline Ulster & 0.74 & 0.81 & 0.74 & 0.63 & 0.86 & 0.23 \\
\hline University College London & 0.94 & 0.34 & 0.34 & 0.83 & 1.00 & 0.17 \\
\hline Warwick & 0.50 & 0.23 & 0.23 & 0.89 & 1.00 & 0.12 \\
\hline West London & 0.44 & 0.83 & 0.44 & 0.78 & 0.59 & -0.19 \\
\hline West of England & 0.71 & 0.77 & 0.71 & 0.65 & 1.00 & 0.36 \\
\hline West of Scotland & 0.40 & 0.77 & 0.40 & 0.80 & 0.73 & -0.07 \\
\hline Westminster & 0.60 & 0.91 & 0.60 & 0.70 & 0.75 & 0.05 \\
\hline Winchester & 0.27 & 0.29 & 0.27 & 0.87 & 0.54 & -0.32 \\
\hline Worcester & 0.30 & 0.46 & 0.30 & 0.85 & 0.69 & -0.16 \\
\hline York & 0.34 & 0.18 & 0.18 & 0.91 & 0.88 & -0.03 \\
\hline York St John & 0.23 & 0.25 & 0.23 & 0.89 & 0.59 & -0.30 \\
\hline
\end{tabular}




\section{References}

Adler N, Golany B (2001) Evaluation of deregulated airline networks using data envelopment analysis combined with principal component analysis with an application to Western Europe. Eur J Oper Res 132(2):260-273

Adler N, Golany B (2002) Including principal component weights to improve discrimination in data envelopment analysis. J Oper Res Soc 53(9):985-991

Adler N, Yazhemsky E (2010) Improving discrimination in data envelopment analysis: PCA-DEA or variable reduction. Eur J Oper Res 202(1):273-284

Agasisti T, Haelermans C (2016) Comparing efficiency of public universities among European countries: different incentives lead to different performances. High Educ Quart 70:81-104

Bana e Costa C (1996) Les problématiques de l'aide à la décision: Vers l'enrichissement de la trilogie choix-tri-rangement. RAIRO Oper Res 30:191-216

Banker R, Charnes A, Cooper W (1984) Some models for estimating technical and scale inefficiencies in data envelopment analysis. Manage Sci 30:1078-1092

Banker R, Charnes A, Cooper W, Swarts J, Thomas D (1989) An introduction to data envelopment analysis with some of its models and their uses. In: Chan J, Patton J (eds) Research in governmental and nonprofit accounting. JAI Press, Greenwich, pp 125-163

Bougnol ML, Dulá JH (2015) Technical pitfalls in university rankings. High Educ 69(5):859-866

Bowden R (2000) Fantasy Higher Education: university and college league tables. Qual High Educ 6:41-60

Brans J-P, Mareschal B (1994) The PROMCALC \& GAIA decision support system for multicriteria decision aid. Decis Support Syst 12:297-310

Brans J-P, Mareschal B (2005) PROMETHEE methods. In: Figueira J, Greco S, Ehrgott M (eds) Multiple criteria decision analysis: state of the art surveys. Springer, New York

Brans J-P, Vincke P (1985) A preference ranking organisation method. Manag Sci 31:647-656

Charnes A, Cooper W, Rhodes E (1978) Measuring the efficiency of decision making units. Eur J Oper Res 2:429-444

Charnes A, Cooper W, Golany B, Seiford L, Stutz J (1985) Foundations of data envelopment analysis for Pareto-Koopmans efficient empirical production functions. J Econom 30:91-107

Chen Y, Iqbal Ali A (2002) Output-input ratio analysis and DEA frontier. Eur J Oper Res 142:476-479

Cook W, Tone K, Zhu J (2014) Data envelopment analysis: prior to choosing a model. Omega 44:1-4

Cooper WW, Seiford LM, Zhu J (2004) Data envelopment analysis. In: Handbook on data envelopment analysis. Springer, New York

Cooper W, Seiford L, Tone K (2007) Data envelopment analysis, 2nd edn. Springer, New York

da Rocha P, Barros A, Silva G, Costa H (2016) Analysis of the operational performance of brazilian airport terminals: a multicriteria approach with De Borda-AHP integration. J Air Transp Manag $51: 19-26$

De Witte K, Hudrlikova L (2013) What about excellence in teaching? A benevolent ranking of universities. Scientometrics 96:337-364

Dyson R, Allen R, Camanho A, Podinovski V, Sarrico C, Shale E (2001) Pitfalls and protocols in DEA. Eur J Oper Res 132:245-259

Filippakou O, Tapper T (2015) Mission groups and the new politics of British higher education. High Educ Quart 69:121-137

Galariotis E, Guyot A, Doumpos M, Zopounidis C (2016) A novel multi-attribute benchmarking approach for assessing the financial performance of local governments: empirical evidence from France. Eur J Oper Res 248:301-317
Giannoulis C, Ishizaka A (2010) A Web-based decision support system with ELECTRE III for a personalised ranking of British universities. Decis Support Syst 48:488-497

Hazelkorn E (2007) The impact of league tables and ranking systems on higher education decision making. High Educ Manag Policy 19:1-24

Huisman J, de Boer H, Bótas P (2012) Where do we go from here? The future of English higher education. High Educ Quart 66:341-362

Ishizaka A, Nemery P (2011) Selecting the best statistical distribution with PROMETHEE and GAIA. Comput Ind Eng 61:958-969

Ishizaka A, Nemery P (2013) Multi Criteria Decis Anal. Wiley, Chichester

Ishizaka A, Pereira V (2016) A fair and transparent employee performance management system based on multi-criteria decision analysis and visual techniques. Int J Manpow 37:628-659

Ishizaka A, Siraj S, Nemery P (2016) Which energy mix for the UK? An evolutive descriptive mapping with the integrated GAIA-AHP visualisation tool. Energy 95:602-611

Kaycheng S (2015) Multicolinearity and indicator redundancy problem in world university rankings: an example using times higher education world university ranking 2013-2014 data. High Educ Quart 69:158-174

Keeney R (1992) Value-focused thinking: a path to creative decision making. Harward University Press, Cambridge

Lenartowicz M (2015) The nature of the university. High Educ 69:947961

Longaray A, Ensslin L, Ensslin S, da Rosa I (2015) Assessment of a Brazilian public hospital's performance for management purposes: a soft operations research case in action. Oper Res Health Care 5:28-48

Mareschal B, Nemery P, Ishizaka A (2010) Unification of problem formulation with PROMETHEE. In: Gülpinar N, Cordoba-Pachon J-R (eds) Keynotes and extended abstracts of the OR fifty-two. The OR Society, Royal Holloway

Marginson S (2007) Global university rankings: implications in general and for Australia. J High Educ Policy Manag 29:131-142

Middlehurst R (2013) Changing internal governance: are leadership roles and management structures in United Kingdom universities fit for the future? High Educ Quart 67:275-294

Mizobuchi H (2014) Measuring world better life frontier: a composite indicator for OECD better life index. Soc Indic Res 118(3):9871007

Muñiz MA (2002) Separating managerial inefficiency and external conditions in data envelopment analysis. Eur J Oper Res 143(3):625-643

Nardo M, Saisana M, Saltelli A, Tarantola S, Hoffman A, Giovannini E (2008) Handbook on constructing composite indicators. OECDJRC, Paris

Nemery P, Ishizaka A, Camargo M, Morel L (2012) Enriching descriptive information in ranking and sorting problems with visualizations techniques. J Model Manag 7:130-147

Oswald A (2001) An economist's view of university league tables. Public Money Manag 21:5-6

Podinovski VV (2016) Optimal weights in DEA models with weight restrictions. Eur J Oper Res 254:916-924

Pomerol JC, Barba-Romero S (2000) Multicriterion decision in management: principles and practice. Kluwer Academic Publishers, Dordrecht

Ray SC, Chen L (2015) Data envelopment analysis for performance evaluation: a child's guide. In: Benchmarking for performance evaluation. Springer, India, pp 75-116

Roy B (1981) The optimisation problem formulation: criticism and overstepping. J Oper Res Soc 32:427-436

Shattock M (2013) University governance, leadership and management in a decade of diversification and uncertainty. High Educ Quart $67: 217-233$ 
Steiner L, Sundström A, Sammalisto K (2013) An analytical model for university identity and reputation strategy work. High Educ 65:401-415

Taylor P, Braddock R (2007) International university ranking systems and the idea of university excellence. J High Educ Policy Manag 29:245-260

Tezel A, Koskela L, Tzortzopoulos P (2016) Visual management in production management: a literature synthesis. J Manuf Technol Manag 27:766-799

Thanassoulis E, Boussofiane A, Dyson R (1995) Exploring output quality targets in the provision of perinatal care in England using data envelopment analysis. Eur J Oper Res 80:588-607

Thanassoulis E, Kortelainen M, Johnes G, Johnes J (2011) Costs and efficiency of higher education institutions in England: a DEA analysis. J Oper Res Soc 62(7):1282-1297

Thomas J, Cook K (2006) A visual analytics agenda. IEEE Comput Graph Appl 26:10-13

Tofallis C (2008) Selecting the best statistical distribution using multiple criteria. Comput Ind Eng 54:690-694
Tofallis C (2012) A different approach to university rankings. High Educ 63:1-18

Ueda T, Hoshiai Y (1997) Application of principal component analysis for parsimonious summarization of DEA inputs and/or outputs. J Oper Res Soc Jpn 40(4):466-478

Vaughn J (2002) Accreditation, commercial rankings, and new approaches to assessing the quality of university research and education programmes in the United states. High Educ Eur 27:433-441

Wallenius J, Dyer J, Fishburn P, Steuer R, Zionts S, Deb K (2008) Multiple criteria decision making, multiattribute utility theory: recent accomplishments and what lies ahead. Manag Sci 54:1336-1349

Yorke M (1997) A good league table guide. Qual Assur Educ 5:61-72 